\title{
Direct Flow Medical vs. Edwards Sapien 3 Prosthesis: A Propensity Matched Comparison on Intermediate Safety and Mortality
}

\author{
Christoph Edlinger 1,2,3,4*, Marwin Bannehr ${ }^{1,2,4}$, Bernhard Wernly ${ }^{3,5}$, Tanja Kücken 1,2,4, \\ Maki Okamoto ${ }^{1,2,4}$, Michael Lichtenauer ${ }^{3}$, Valentin Hähnel ${ }^{1,2,4}$, David Reiners ${ }^{1,2,4}$, \\ Michael Neuss ${ }^{1,2,4}$ and Christian Butter ${ }^{1,2,4}$ \\ ${ }^{1}$ Department of Cardiology, Heart Center Brandenburg, Bernau/Berlin, Germany, ${ }^{2}$ Brandenburg Medical School (MHB) \\ "Theodor Fontane", Neuruppin, Germany, ${ }^{3}$ Clinic of Internal Medicine II, Department of Cardiology, Paracelsus Medical \\ University of Salzburg, Salzburg, Austria, ${ }^{4}$ Faculty of Health Sciences Brandenburg, Brandenburg Medical School Theodor \\ Fontane, Brandenburg, Germany, ${ }^{5}$ Department of Anaesthesiology, Perioperative Medicine and Intensive Care Medicine, \\ Paracelsus Medical University of Salzburg, Salzburg, Austria
}

OPEN ACCESS

Edited by:

Joshua D. Hutcheson, Florida International University, United States

Reviewed by:

Kevin Teoh,

Southlake Regional Health Center, Canada

Antonino S. Rubino,

University of Campania Luigi Vanvitelli, Italy

${ }^{*}$ Correspondence: Christoph Edlinger christophroland.edlinger@ immanuelalbertinen.de

Specialty section This article was submitted to

Heart Valve Disease,

a section of the journal

Frontiers in Cardiovascular Medicine

Received: 24 February 2021 Accepted: 24 May 2021

Published: 18 June 2021

Citation:

Edlinger C, Bannehr M, Wernly B, Kücken T, Okamoto M, Lichtenauer M, Hähnel V, Reiners D, Neuss M and Butter C (2021) Direct Flow Medical vs. Edwards Sapien 3 Prosthesis: A Propensity Matched Comparison on Intermediate Safety and Mortality. Front. Cardiovasc. Med. 8:671719. doi: $10.3389 /$ fcvm.2021.671719
Aims: To compare intermediate performance and mortality rates in patients, who underwent transcatheter aortic valve implantation (TAVI) with two different types of prostheses: Edwards Sapien 3 (ES3) and Direct Flow Medical (DFM).

Methods and Results: 42 consecutive patients implanted with a DFM prosthesis for severe aortic stenosis were matched 1:1 with an equal number of patients, who received an ES3 during the same period. Primary endpoint was mortality. MACE, as a composite of all-cause death, stroke, and re-do-procedure (valve-in-valve), was defined as secondary endpoint. Moreover, we compared NYHA class, NT-proBNP-levels and the extent of restenosis. Patients were followed for 2 years. DFM patients showed echocardiographic elevated mean pressure gradients compared to ES3 patients before discharge (11.2 $\mathrm{mmHg} \pm 5.3$ vs. $3.5 \mathrm{mmHg} \pm 2.7 ; p<0.001$ ) and upon 6-months follow-up (20.3 $\mathrm{mmHg} \pm 8.8$ vs. $12.3 \mathrm{mmHg} \pm 4.4 ; p<0.001)$. ES3 candidates showed superior NYHA class at follow-up $(p=0.001)$. Kaplan-Meier analysis revealed significantly worse survival in patients receiving a DFM prosthesis compared to ES3 (Breslow $p=0.020$ ). MACE occurred more often in DFM patients compared to ES3 (Breslow $p=0.006$ ).

Conclusions: Patients receiving DFM valve prostheses showed worse survival and higher rates in MACE compared to ES3. Prosthesis performance regarding mean pressure gradients and patients' NYHA class also favored ES3.

Keywords: aortic stenosis, TAVI, direct flow medical, Edwards Sapien 3, mortality, MACE, survival

\section{INTRODUCTION}

Transfemoral aortic valve implantation (TAVI) represents an outstanding success story in interventional cardiology in recent years. Since the first implantation by Cribier et al. (1), there has been an enormous increase in clinical and scientific experience, and the method now represents an indispensable standard therapy (1-4).

Over the years, different types of prostheses have been established as most frequently implanted products worldwide: Namely, the self-expanding Medtronic Corevalve prosthesis 
(MVC) (Medtronic Inc. Minneapolis, MN, USA) and the balloon-expanding Edwards Sapien 3 prosthesis (ES3) (Edwards Life Sciences Inc. Irvine, CA, USA). In addition, there is a certain number of other models with various potential advantages, such as the Direct Flow medical prosthesis (DFM) (DFM Santa Rosa, CA, USA). This type of prosthesis was intended to offer safety improvements due to its non-metallic construction, but above all due to its ability to inflate and deflate, allowing the system to be repositioned and retrieved during the intervention, if necessary, in order to figure out an optimal position.

Although data in short-term treatment has been very promising, especially concerning lower rates of postinterventional pacemaker implantation, the product did not achieve a sustainable breakthrough and was consequently withdrawn from the market $(5,6)$. Regarding the direct comparison of the DFM prosthesis only comparative data on short-term treatment exist, whereas little is known about intermediate safety and mortality (7). Nevertheless, a considerable number of patients who have been implanted with this type of prosthesis are still encountered in clinical follow-ups. Since its introduction in 2013 until its withdrawal from the market in late $2016 \sim 3.000$ DFM protheses have been implanted worldwide $(32,33)$. With an aggregated survival of TAVI patients at 1-, 2-, 3-, and 5-years being 83, 75, 65, and 48\%, respectively, numerous patients implanted with DFM valves are considered to be still alive (8).

Now that there is a considerable amount of intermediate data in the field of TAVI, the question of intermediate performance is becoming increasingly important.

It could be shown that patients with paravalvular regurgitation have a significantly worse outcome (9). Kang et al. recently presented the Dicrotic AR Index, a hemodynamic tool for the prediction of paravalvular regurgitation following TAVI (10). How to deal with repeatedly increased gradients, on the other hand, seems particularly challenging, since an increase in mean pressure gradients (PGmean) may also be related to a postinterventional improvement of left ventricular function. Thus, in contrast to conventional aortic valve replacement, there are currently no reference values from which a regular TAVI function can be conclusively assessed. Protheses degeneration is a known problem that occurs over the years. However, little has been reported with regard to DFM valves in particular.

In our current study we investigated the intermediate course of patients, who had been implanted with a DFM and those who received an ES3, based on a 1:1 propensity matched score. We compared performance, safety and overall all-cause mortality.

\section{METHODS}

\section{Study Design}

In this retrospective observational comparative-cohort study we analyzed the clinical course of patients who were treated at our center from $06 / 2013$ to $12 / 2016$. A total number of 721 individuals could be identified within this period. Of these, each received either a DFM or an ES3 prosthesis. Patients were followed for 2-year survival. Fifty patients who received a DFM were matched 1:1 with those who received an ES3. Within

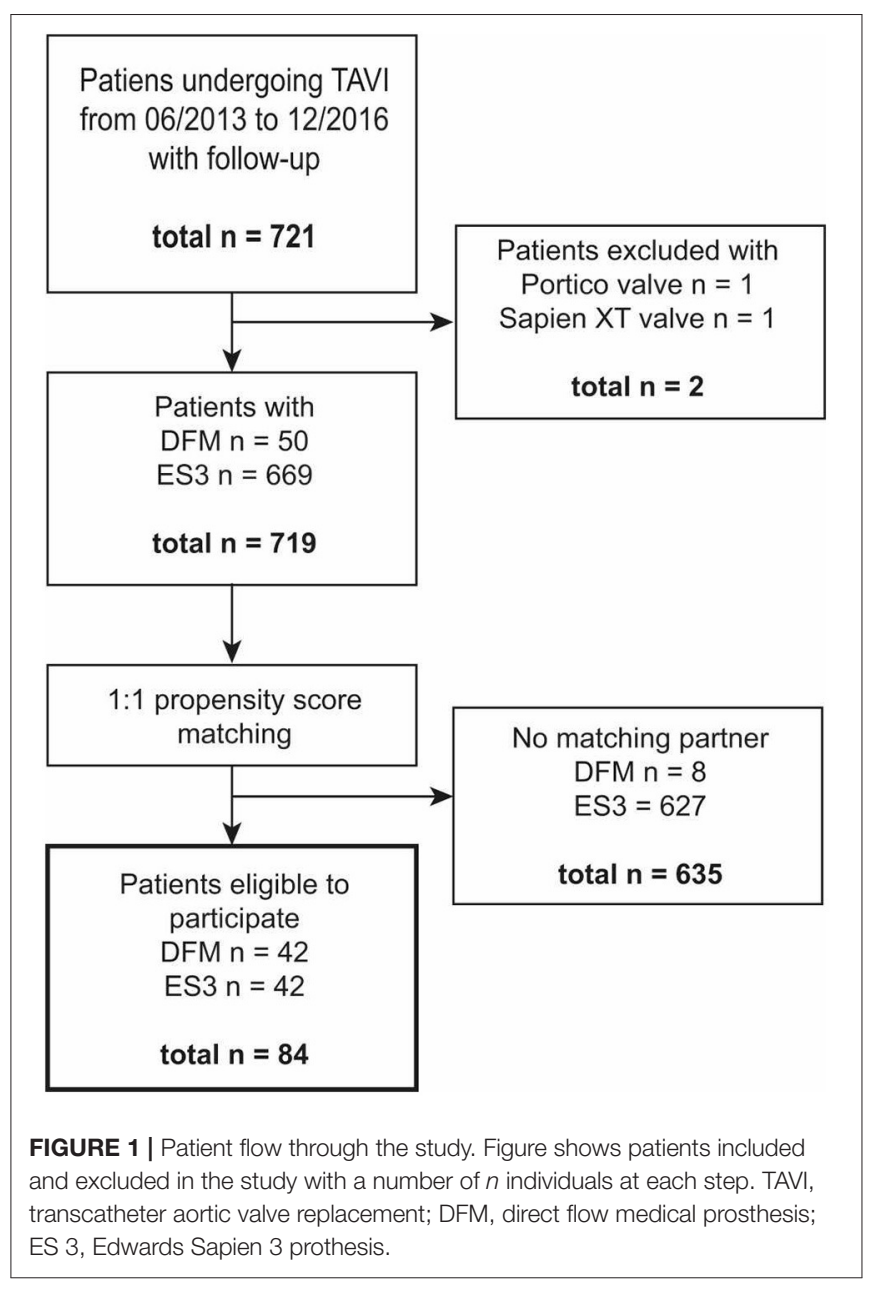

the DFM group, eight patients had to be excluded because no appropriate matching partner could be identified. Thus, a total of 84 patients were included in our analyses as the defined study population (Figure 1).

The case of each individual patient was discussed in advance by our interdisciplinary heart team, consisting of cardiologists and heart surgeons, where the consensus for a TAVI procedure had been set.

All patients underwent transthoracic echocardiography, in order to confirm the diagnosis. Moreover, a multi-slice computed tomography was performed for assessment of dimensions and morphology of the aortic valve and aorta. The estimation of surgical risk was performed by using the EuroScore (11). The definition of severe aortic stenosis was made according to the current guideline of the European Society of Cardiology (PGmean $>40 \mathrm{mmHg}$ or peak jet velocity $>4.0 \mathrm{~m} / \mathrm{s}$ or aortic valve area $</=0.8 \mathrm{~cm}^{2}$ or aortic valve area index $<0.5$ $\left.\mathrm{cm}^{2} / \mathrm{m}^{2}\right)(12)$.

The decision on the type of prosthesis to be implanted was made for each individual case by the performing interventionalist. Clinical prerequisites (NYHA class, LVEF, etc.) were identical. The rationale for valve selection was based 


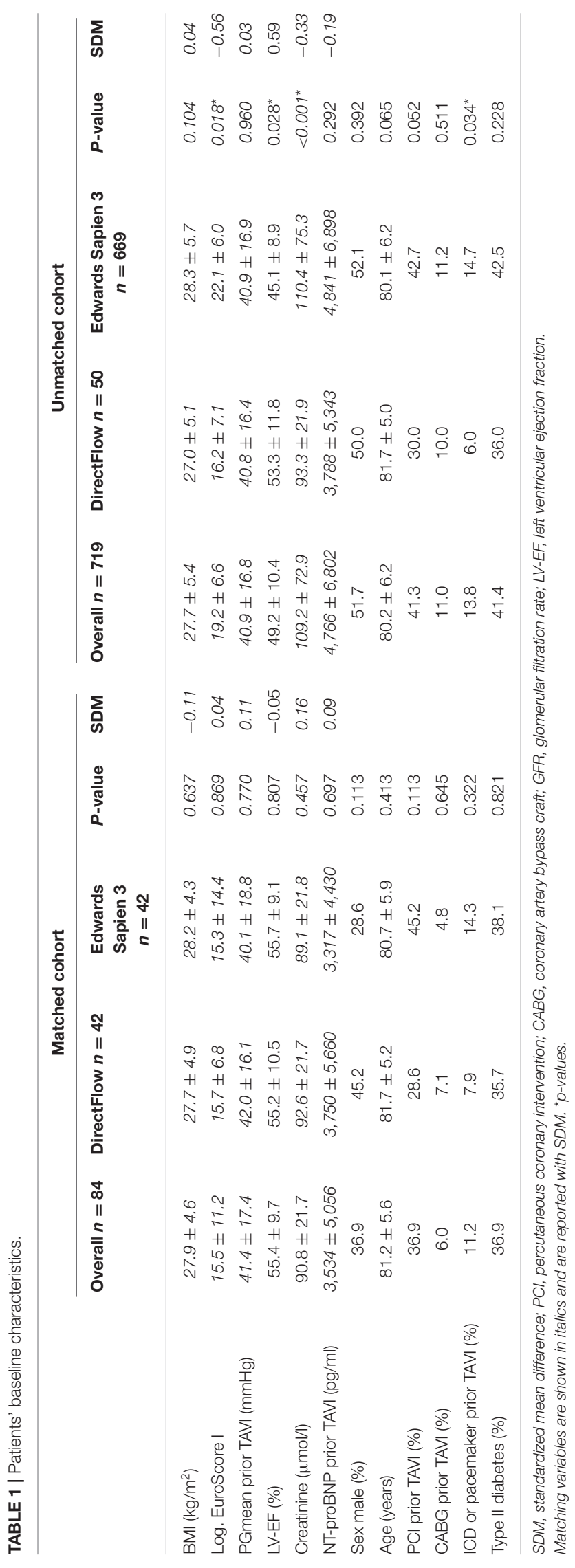

TABLE 2 | Volume of calcification (matched cohort).

\begin{tabular}{lcccc}
\hline & Overall & DirectFlow & $\begin{array}{c}\text { Edwards } \\
\text { Sapien 3 }\end{array}$ & P-value \\
\hline LVOT Calcium $\left(\mathrm{mm}^{3}\right)$ & $8.1 \pm 17.7$ & $10.6 \pm 21.3$ & $5.4 \pm 12.7$ & 0.210 \\
Annulus Calcium $\left(\mathrm{mm}^{3}\right)$ & $41.8 \pm 51.3$ & $47.9 \pm 60.9$ & $35.4 \pm 38.6$ & 0.309 \\
Leaflet Calcium $\left(\mathrm{mm}^{3}\right)$ & $333.9 \pm 230.5$ & $415.9 \pm 243.0$ & $247.3 \pm 182.7$ & $0.001^{*}$ \\
\hline
\end{tabular}

${ }^{*} p$-values.

on anatomical features in pre-procedural multi slice computed tomography imaging. Patients who showed complicating anatomical conditions (asymmetry, spur of calcification protruding into the outflow tract or bicuspid valve) were not suitable for a DFM prothesis. For the purpose of quantification of valvular calcification, the aortic root was separated into three regions along its long axis: annulus, leaflets, and left ventricular outflow tract. Three mensio Valves software (PIE Medical Imaging, Maastricht, Netherlands) was used to measure calcification with a $550 \mathrm{HU}$ threshold.

Prior written consent was obtained from all patients both for the TAVI procedure and for the use of data.

The study was conducted in accordance with the guidelines of the Declaration of Helsinki.

\section{Data Collection}

Demographics and clinical data including relevant comorbidities and laboratory results were collected using patient medical records. Follow-up data for survival rates were collected from hospital database and primary care physicians via telephone interview. Patients were followed for all-cause mortality.

Echocardiographic examinations were performed with commercially available ultrasound systems (GE-Vingmed, Vivid 7 and E9, Horten Norway) by trained physicians.

\section{Statistical Analysis}

Data was analyzed using descriptive statistics, with categorical variables presented as absolute values and frequencies (\%) and continuous variables presented as means with standard deviation or median and interquartile range (IQR) when appropriate.

A propensity score was calculated using logistic regression from the covariates Euroscore, body mass index (BMI), creatinine, left ventricular ejection fraction (LVEF), PGmean, and N-terminal pro brain natriuretic peptide (NT-proBNP). A matched cohort was obtained using the "nearest neighbor" method. The maximum allowed distance was a $\Delta$ in propensity score of 0.001 . Since the variable age is already included in the EuroScore as a continuous value it has not been taken into account for matching. Comparisons between groups were carried out using Student's $t$-test for continuous variables and a Mann-Whitney- $U$-test for categorical variables. Survival analysis data is presented as Kaplan-Meier curves. A two-tailed $p$-value of $<0.05$ was considered statistically significant. All statistical tests were performed using IBM SPSS Statistics software version 24.0 (IBM Corporation, Armonk, NY, USA). 
TABLE 3 | TAVI performance-Comparison DirectFlow vs. Edwards Sapien 3 (matched cohort).

\begin{tabular}{|c|c|c|c|c|}
\hline & Overall & DirectFlow & Edwards Sapien 3 & $P$-value \\
\hline Valve size & $\mathrm{N} / \mathrm{A}$ & $\begin{array}{l}23 \mathrm{~mm} n=1 \\
25 \mathrm{~mm} n=21 \\
27 \mathrm{~mm} n=19 \\
29 \mathrm{~mm} n=1\end{array}$ & $\begin{array}{l}23 \mathrm{~mm} n=17 \\
26 \mathrm{~mm} n=20 \\
29 \mathrm{~mm} n=5\end{array}$ & $\mathrm{~N} / \mathrm{A}$ \\
\hline PGmean prior TAVI (mmHg) & $41.4 \pm 17.4$ & $42.0 \pm 16.1$ & $40.1 \pm 18.8$ & 0.770 \\
\hline PGmean post TAVI (mmHg) & $6.8 \pm 5.5$ & $11.2 \pm 5.3$ & $3.5 \pm 2.7$ & $<0.001^{\star}$ \\
\hline PGmean at 6-months FU TAVI (mmHg) & $16.2 \pm 7.9$ & $20.3 \pm 8.8$ & $12.3 \pm 4.4$ & $<0.001^{*}$ \\
\hline NYHA at admission (\%) & & & & 0.097 \\
\hline$\|$ & 13.0 & 10.5 & 15.4 & \\
\hline III & 77.9 & 73.7 & 82.1 & \\
\hline IV & 9.1 & 15.8 & 2.6 & \\
\hline NYHA at 6-months FU (\%) & & & & $<0.001^{*}$ \\
\hline$\|$ & 41.8 & 20.5 & 52.5 & \\
\hline III & 58.2 & 79.5 & 37.5 & \\
\hline IV & 0 & 0 & 0 & \\
\hline NT-proBNP prior TAVI (pg/ml) & 1.819 (IQR 3.498) & 1.840 (IQR 2.631) & 1.669 (IQR 3.689) & 0.847 \\
\hline NT-proBNP at discharge (pg/ml) & 1.576 (IQR 2.740) & 2.230 (IQR 2.986) & 1.169 (IQR 2.296) & 0.226 \\
\hline NT-proBNP at 6-months FU (pg/ml) & 633 (IQR 1.439) & 624 (IQR 2.909) & 681 (IQR 991) & 0.414 \\
\hline Post-procedural AR/PVL (\%) & 44.0 & 42.9 & 45.3 & 0.933 \\
\hline Minimal & 21.4 & 16.7 & 26.2 & \\
\hline Mild & 17.9 & 21.4 & 14.3 & \\
\hline Moderate & 4.8 & 4.8 & 4.8 & \\
\hline PPI post TAVI (\%) & 13.1 & 7.1 & 19.0 & 0.116 \\
\hline Post-procedural LBBB TAVI (\%) & 15.5 & 14.3 & 16.7 & 0.500 \\
\hline Hospital stay (days) & $10.9 \pm 6.2$ & $10.6 \pm 6.1$ & $11.2 \pm 6.3$ & 0.676 \\
\hline Valve in valve re-do procedure $(n)$ & 4 & 3 & 1 & 0.308 \\
\hline $\operatorname{MACE}(n)$ & 12 & 10 & 2 & $0.013^{\star}$ \\
\hline All-cause death $(n)$ & 10 & 8 & 2 & $0.044^{*}$ \\
\hline Stroke $(n)$ & 2 & 2 & 0 & 0.247 \\
\hline
\end{tabular}

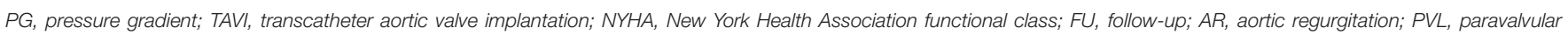
leakage; PPI, permanent pacemaker implantation; LBBB. left bundle branch block; MACE, major adverse cardiac event. ${ }^{\star} p$-values.

\section{Prosthesis Types}

The DFM prosthesis was a percutaneous valve with a nonmetallic design. The valve apparatus itself is based on bovine pericardium (13). The basic structure of the prosthesis is made of dacron/polyester, whereby two rings have been designed of which the upper ring is positioned in the aorta and the lower ring on the side of the ventricle. Both rings can be individually controlled and unfolded.

A total of four sizes were available $(23 / 25 / 27 / 29 \mathrm{~mm})$.

Immediately after the balloon valvuloplasty, the valve was positioned using the guiding catheter. The rings were first filled with a saline solution to a pressure of 12 ATM and could be readjusted, if necessary, until the desired position was reached. Once the ideal position had been found, the saline solution was exchanged for a polymer while maintaining the pressure, which led to the hardening of the prosthesis in position (14).

The ES3 has already been well-described elsewhere (15-17). In brief, it is a balloon expanding valve of the second generation. The frame is made of cobalt, whereas the valve apparatus is made of bovine pericardium. This type of prosthesis is available in four sizes $(20 / 23 / 26 / 29 \mathrm{~mm})$.

\section{RESULTS}

A total of 84 patients were included in this study. Patients were at advanced age and a majority obese with numerous comorbidities as typical for a TAVI cohort. Table $\mathbf{1}$ provides a detailed overview of patient characteristics before and after propensity score matching. While patients who received a DFM showed lower EuroScore, impaired LVEF, better renal function, and a higher prevalence of cardiac devices, there were no significant differences between the two groups after matching, with regard to baseline characteristics.

Calcium volume on computed tomography differed between groups with respect to valvular leaflets $(415.9 \pm 243.0$ vs. $247.3 \pm$ $182.7 \mathrm{~mm}^{3} ; p=0.001$ ) with a higher calcium load in the DFM group. LVOT and annular calcium did not differ significantly (Table 2).

TAVI performance differed significantly in regard to both prosthesis types: Patients who received DFM showed increased PGmean in transthoracic echocardiography compared to ES3, both before discharge from hospital $(11.2 \pm 5.3$ vs. $3.5 \pm 2.7$; 
TABLE 4 | Anticoagulants and thrombocyte aggregation inhibitors post TAVI (matched cohort).

\begin{tabular}{lcccc}
\hline & Overall & DirectFlow & $\begin{array}{c}\text { Edwards } \\
\text { Sapien 3 }\end{array}$ & P-value \\
\hline ASS (\%) & 56.8 & 60.0 & 53.7 & 0.567 \\
Clopidogrel (\%) & 88.9 & 95.0 & 82.9 & 0.086 \\
Ticagrelor (\%) & 1.2 & 0 & 2.4 & 0.323 \\
Prasugrel (\%) & 0 & 0 & 0 & N/A \\
DOAK (\%) & 6.2 & 0 & 12.2 & $0.024^{*}$ \\
Apixaban (\%) & 1.2 & 0 & 2.4 & \\
Rivaroxaban (\%) & 3.7 & 0 & 7.3 & \\
Dabigatran (\%) & 0 & 0 & 0 & 0.933 \\
Edoxaban (\%) & 1.2 & 0 & 2.4 & 0.429 \\
Vitamin Kantagonist & 37.0 & 37.5 & 36.6 & 0.323 \\
Low molecular heparin & 30.9 & 35.0 & 26.8 & 2.4 \\
Fondaparinux & 1.2 & 0 & & \\
\hline
\end{tabular}

Standard thrombocyte aggregation inhibitor regimen was ASS plus Clopidogrel for 3-6 months post-TAVI unless there was an indication for anticoagulation (in patients with atrial fibrillation, thrombosis, or pulmonary embolism), another thrombocyte aggregation inhibitor regimen required according to guidelines (prior myocardial infarction, previous coronary intervention in Clopidogrel non-responders), or an allergic reaction to one of the substances. Patients with indication for anticoagulation received vitamin K antagonist plus Clopidogrel for 3-6 months as first line therapy. DOAK, direct oral anticoagulant. ${ }^{*} p$-values.

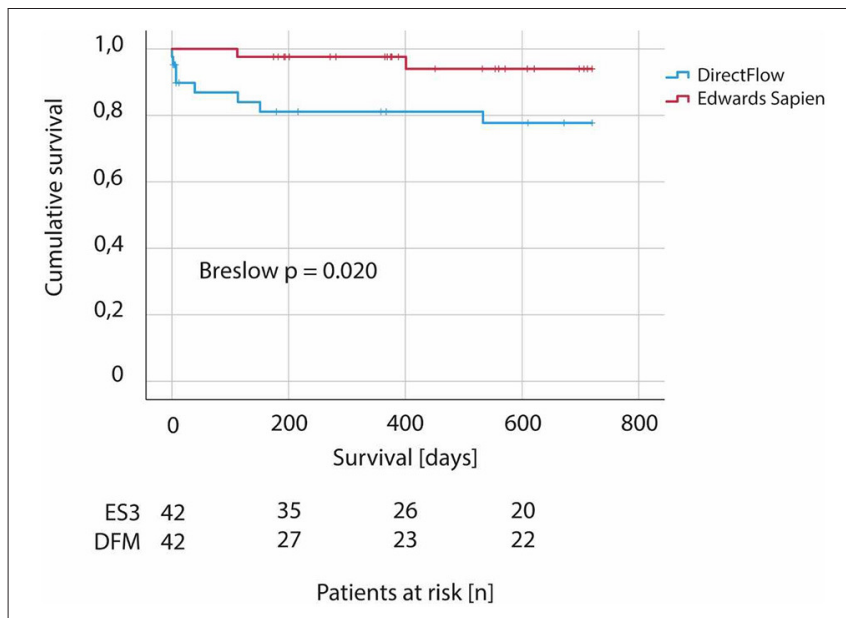

FIGURE 2 | Two-year survival in patients undergoing TAVI-comparison between DirectFlow and Edwards Sapien 3. Kaplan-Meier analysis according to type of valve (DirectFlow vs. Edwars Sapien 3). $N=84$.

$p \leq 0.001)$ and at 6 -month follow-up $(20.3 \pm 8.8$ vs. $12.3 \pm 4.4$; $p<0.001$ ) (Table 3).

Patients improved in NYHA functional class in both groups at 6-months compared to hospital admission. Patients receiving an ES3 were superior compared to DFM (Table 3).

Overall median NT-proBNP levels declined within 6 months following TAVI (1.819 pg/ml [IQR 3.498] vs. $633 \mathrm{pg} / \mathrm{ml}$ [IQR 1.439]). There was no statistically significant difference between groups, while there was a trend toward lower levels in those with ES3 (Table 3).

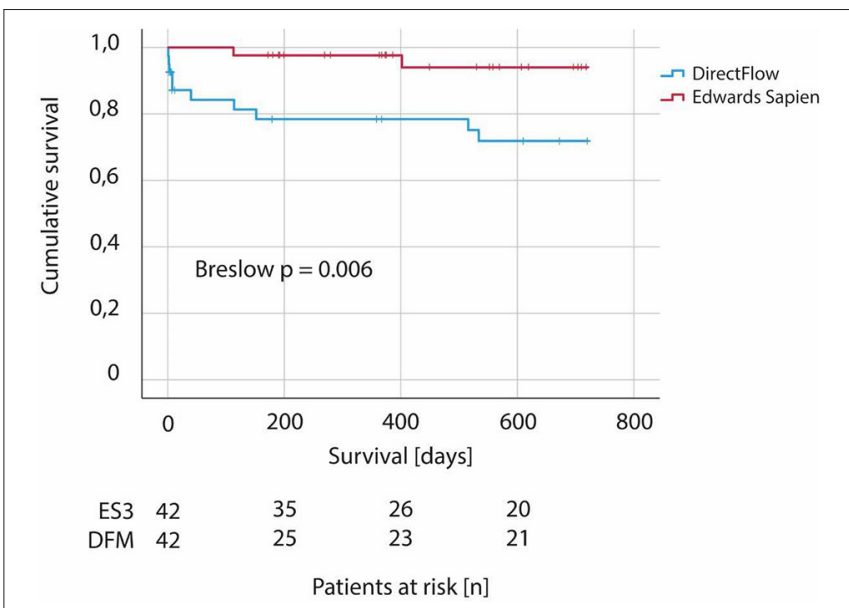

FIGURE 3 | Two-year MACE in patients undergoing TAVI-comparison between DirectFlow and Edwards Sapien 3. MACE defined as composite of all-cause death, stroke, and re-do-procedure (valve-in-valve) within 2 years from implantation of first valve (DirectFlow vs. Edwars Sapien 3). $N=84$.

None of the calcification variables assessed were predictive of having a post-procedural prothesis PGmean $>20 \mathrm{mmHg}$. Leaflet calcium volume correlated only weakly with post-procedural PGmean ( $r=0.27, p=0.029)$.

Residual aortic regurgitation and/or paravalvular leakage did not differ between groups (Table 3 ).

Permanent pacemaker implantation was necessary in $7.1 \%$ individuals with a DFM prothesis compared to $19.0 \%$ with an ES3 $(p=0.116)$. New complete left bundle branch block occurred in $14.3 \%$ (DFM) vs. $16.7 \%$ (ES3) of patients $(p=0.500)$.

Three patients underwent valve in valve re-do procedure in the DFM group compared one in the ES3 group. Duration of hospital stay did not differ between groups (Table 3 ). Patients presented again with symptomatic heart failure and markedly elevated pressure gradients. None of the four cases were reintervened because of paravalvular leakage or relevant aortic regurgitation.

Thrombocyte aggregation inhibitors post TAVI did not differ between groups. While a significant number of patients received direct oral anticoagulants in the ES3 group there were more patients discharged on low molecular heparin in the DFM group (Table 4).

\section{Survival Analysis}

Out of all 84 patients 10 died within the 2 -year follow-up period (8 DFM, 2 ES3).

As shown in Figure 2 Kaplan-Meier survival analysis showed significantly worse survival in patients receiving a DFM prosthesis compared to ES3 (Breslow $p=0.020$ ).

MACE, as a composite of all-cause death, stroke, and re-doprocedure (valve-in-valve), occurred more often if a DFM was the prosthesis of choice compared to ES3 (10 DFM, 2 ES3; Breslow $p=0.006$ ) (Figure 3). 


\section{DISCUSSION}

To the best of our knowledge, this is the first study to compare the intermediate performance of DFM and ES3 valve prostheses by using propensity score matching. Our findings can be summarized as follows:

(1) Patients with DFM have a higher risk of death within 2 years compared to ES3.

(2) Patients with DFM have a significantly higher risk of suffering a MACE [composed of all-cause death, stroke, and re-do-procedure (valve-in-valve)].

(3) At 6-months follow-up patients with DFM showed a significantly higher PGmean.

(4) The NYHA class was significantly worse in patients with DFM at 6-months follow-up, while differences in NTproBNP levels were not of statistical significance.

While previous studies could document an equivalent performance between the prosthesis types within the early phase of therapy, we saw a significant increase in all-cause mortality in patients who primarily received a DFM within our propensity score matched study population $(5,6,14)$.

At 6-months follow-up already, we could observe significantly increased pressure gradients in DFM patients. Especially since we also observed higher NYHA classes at this time, we assume that there is a significantly worse hemodynamic performance, which apparently already occurs after only a few months. This significant hemodynamic disadvantage may have a substantial impact on the patients' clinical benefit and ultimately result in a significantly higher mortality in DFM compared to ES patients.

It may sound tempting to have a prosthesis available, that is both non-metallically designed and that can be repositioned, the product obviously has some weak points. If an increased gradient has been detected, one is initially inclined to think of a thrombogenic etiology first. According to current data however, manifest thromboses of the valves leading to clinical symptoms are a rare event after TAVI (18). In contrast, partial thromboses are encountered significantly more frequently, which usually do not have a clinical impact (19). Since we did not have any relevant differences in coagulation management within the two groups, we consider a thrombotic etiology unlikely.

On the one hand, we assume that the material used might itself be more prone to faster degeneration. Comparable data on primary degeneration of that part of the valve made from animal pericardium exist from conventional aortic valve replacement (20-23). When these processes begin and when clinical relevance is reached remains to be determined in regard to TAVI, at least in the case of prostheses of the latest generation (24-26).

On the other hand, the DFM prosthesis cannot be inserted into the left ventricular outflow tract with the same pressure as the ES3 or other metal-based products, so the effective opening area might be smaller right from the start. We assume that hemodynamically, an effect comparable to that known from conventional surgical aortic valve replacement in case of a prosthesis mismatch could occur.

A basic difference can already be found in the selection of the size of the prosthesis. In principle, the balloon-expandable
ES3 valve is selected according to the annular area, not the circumference (i.e. perimeter); whereas the DFM is selected according to the perimeter-not the area. If one calculates "roughly," the S3 $23 \mathrm{~mm}$ is implanted at a perimeter of $75-83 \mathrm{~mm}$, the S3 $26 \mathrm{~mm}$ and DFM Flow $27 \mathrm{~mm}$ for a perimeter of $79-85 \mathrm{~mm}$. In the end, this difference is reflected in the effective opening area of the DFM. According to current literature mean opening area is $1.6 \mathrm{~cm}^{2} \pm 0.4$ and thus the same size as smallest version of ES3 $(23 \mathrm{~mm})(27,28)$.

An interesting side finding of our work is the fact that the three patients in the DFM group with a reasonable clinical intermediate outcome had undergone a "valve in valve" procedure. Already in 2016, our group was able to publish the world's first case of a "valve in valve" implantation after DFM implantation (29). Furthermore, Yap et al. and Karaduman et al. independently reported on the technical challenges of a valve in valve procedure when the first prosthesis was a DFM recently $(30,31)$.

How many of the patients implanted with a DFM prosthesis are actually still alive can only be estimated to a certain extent. An official announcement by the manufacturer states that a total of 2.700 prostheses had been implanted by May 2016 (33). According to the review by Chakos et al. aggregated survival at 1-, 2-, 3-, and 5-years after TAVI were $83,75,65$, and $48 \%$, respectively, for different manufacturers (8).

Thus, it can be concluded that a considerable number are still alive. It seems important to us to follow up these patients carefully and to evaluate whether a "valve-in-valve" procedure can be considered in the case of symptomatic restenosis.

In our cohort two patients who initially received a DFM $25 \mathrm{~mm}$ could be fitted with an ES XT $20 \mathrm{~mm}$ and Medtronic Evolut R $23 \mathrm{~mm}$, one patient who initially had a DFM $27 \mathrm{~mm}$ implanted could also be treated with a Medtronic Evolut R $23 \mathrm{~mm}$. In all cases, the intervention proved to be safe and without complications. For this reason, we assume that patients with DFM can undergo a valve in valve procedure in an experienced center with an acceptable risk, so that at least a therapeutic perspective can be offered to patients with a degenerated DFM prosthesis.

\section{LIMITATIONS}

The main limitations of our study are its retrospective, nonrandomized design, and the single center setting. There was only a limited number of patients who died within the study period. Nevertheless, due to the significant differences in both, mortality and restenosis rates, we are convinced that the conclusions drawn are valid despite the relatively low number of cases. Since the TAVI population is generally an old, correspondingly pre-diseased patient population, natural patient death must be included in the consideration. The first DFM patients within our cohort were implanted as of June 2013. The market launch of the ES3 did not take place until January 2014, so that there is no exact time overlap between the two groups. Propensity score matching did not include prothesis size since direct comparison did not seem 
appropriate. However, as shown in Table 3, there were rather more patients in the ES3 group with smaller protheses, thus size (diameter) itself should not account for the differences we observed.

\section{CONCLUSION}

Patients receiving a DFM valve prosthesis showed worse survival and higher rates in MACE compared to ES3. Valve performance regarding mean pressure gradients and patients' NYHA class also favored ES3. Valve in valve re-do procedures showed to be safe in DFM patients as a bail out option for a degenerate prosthesis.

\section{DATA AVAILABILITY STATEMENT}

The original contributions presented in the study are included in the article/supplementary material, further inquiries can be directed to the corresponding author/s.

\section{REFERENCES}

1. Cribier A, Eltchaninoff H, Bash A, Borenstein N, Tron C, Bauer F, et al. Percutaneous transcatheter implantation of an aortic valve prosthesis for calcific aortic stenosis: first human case description. Circulation. (2002) 106:3006-8. doi: 10.1161/01.CIR.0000047200.36165B8

2. Cribier A, Eltchaninoff H, Tron C, Bauer F, Agatiello C, Sebagh L, et al. Early experience with percutaneous transcatheter implantation of heart valve prosthesis for the treatment of end-stage inoperable patients with calcific aortic stenosis. J Am Coll Cardiol. (2004) 43:698703. doi: 10.1016/j.jacc.2003.11026

3. Leon MB, Smith CR, Mack M, Miller DC, Moses JW, Svensson LG, et al. Transcatheter aortic-valve implantation for aortic stenosis in patients who cannot undergo surgery. N Engl J Med. (2010) 363:1597607. doi: 10.1056/NEJMoa1008232

4. Ribeiro HB, Lerakis S, Gilard M, Cavalcante JL, Makkar R, Herrmann HC, et al. Transcatheter aortic valve replacement in patients with low-flow, lowgradient aortic stenosis: the TOPAS-TAVI registry. J Am Coll Cardiol. (2018) 71:1297-308. doi: 10.1016/j.jacc.2018.01.054

5. Bijuklic K, Tübler TI, Low R, Grube E, Schofer J. Direct flow medical valve. EuroIntervention. (2012) 8:Q75-8. doi: 10.4244/EIJV8SQA13

6. Schofer J, Colombo A, Klugmann S, Fajadet J, Demarco F, Tchétché $\mathrm{D}$, et al. Prospective multicenter evaluation of the direct flow medical transcatheter aortic valve. J Am Coll Cardiol. (2014) 63:763-8. doi: 10.1016/j.jacc.2013.10.013

7. Zhang Y, Pyxaras SA, Wolf A, Schmitz T, Naber CK. Propensity-matched comparison between direct flow medical, medtronic corevalve, and Edwards Sapien XT prostheses: device success, thirty-day safety, and mortality. Catheter Cardiovasc Interv. (2015) 85:1217-25. doi: 10.1002/ccd25831

8. Chakos A, Wilson-Smith A, Arora S, Nguyen TC, Dhoble A, Tarantini G, et al. Long term outcomes of transcatheter aortic valve implantation (TAVI): a systematic review of 5-year survival and beyond. Ann Cardiothorac Surg. (2017) 6:432-43. doi: 10.21037/acs.2017.0910

9. Thourani VH, Kodali S, Makkar RR, Herrmann HC, Williams M, Babaliaros $\mathrm{V}$, et al. Transcatheter aortic valve replacement versus surgical valve replacement in intermediate-risk patients: a propensity score analysis. Lancet. (2016) 387:2218-25. doi: 10.1016/S0140-6736(16)30073-3

10. Kang J, Yun JP, Ki YJ, Lee HS, Han JK, Yang HM, et al. A new hemodynamic index predicting paravalvular regurgitation after TAVR: dicrotic AR index. JACC Cardiovasc Interv. (2020) 13:2711-3. doi: 10.1016/j.jcin.2020.07029

11. Nashef SA, Roques F, Michel P, Gauducheau E, Lemeshow S, Salamon R. European system for cardiac operative risk evaluation (EuroSCORE).

\section{ETHICS STATEMENT}

The study was performed in accordance with the Declaration of Helsinki. The ethics committee advised that no formal vote and no written informed consent beyond the agreement at hospital admission was necessary because data collection and assessment was part of hospital-wide measure of quality management.

\section{AUTHOR CONTRIBUTIONS}

CE coordinated the study, acquisited and analyzed data, wrote the manuscript, and contributed in the final submission. MB analyzed data, prepared figures, and contributed in manuscript preparation. BW analyzed data and contributed in final submission. TK, $\mathrm{MO}, \mathrm{VH}$, and $\mathrm{DR}$ contributed in data acquisition. $\mathrm{ML}$ and $\mathrm{MN}$ revised the article critically for the content. CB planned the study and provided final approval of the article. All authors contributed to the article and approved the submitted version.

Eur J Cardiothorac Surg. (1999) 16:9-13. doi: 10.1016/\$1010-7940(99) 00134-7

12. Baumgartner H, Falk V, Bax JJ, De Bonis M, Hamm C, Holm PJ, et al. 2017 ESC/EACTS Guidelines for the management of valvular heart disease. Eur Heart J. (2017) 38:2739-91. doi: 10.1016/j.rec.2017.12013

13. Bijuklic K, Tuebler T, Reichenspurner H, Treede H, Wandler A, Harreld JH, et al. Midterm stability and hemodynamic performance of a transfemorally implantable nonmetallic, retrievable, and repositionable aortic valve in patients with severe aortic stenosis. Up to 2-year follow-up of the directflow medical valve: a pilot study. Circ Cardiovasc Interv. (2011) 4:595601. doi: 10.1161/CIRCINTERVENTIONS.111964072

14. Hernández-Antolín RA, Salido L, González A, Samaranch N, Palomera A, Zamorano JL. Initial experience with the DirectFlow percutaneous aortic valve in Spain. Rev Esp Cardiol (Engl Ed). (2014) 67:9546. doi: 10.1016/j.rec.2014.06008

15. Mack MJ, Leon MB, Thourani VH, Makkar R, Kodali SK, Russo $\mathrm{M}$, et al. Transcatheter aortic-valve replacement with a balloonexpandable valve in low-risk patients. N Engl J Med. (2019) 380:1695-705. doi: 10.1056/NEJMoa1814052

16. Patel KV, Omar W, Gonzalez PE, Jessen ME, Huffman L, Kumbhani DJ, et al. Expansion of TAVR into low-risk patients and who to consider for SAVR. Cardiol Ther. (2020) 9:377-94. doi: 10.1007/s40119-020-00198-Z

17. Pibarot P, Salaun E, Dahou A, Avenatti E, Guzzetti E, Annabi MS, et al. Echocardiographic results of transcatheter versus surgical aortic valve replacement in low-risk patients: the PARTNER 3 trial. Circulation. (2020) 141:1527-37. doi: 10.1161/CIRCULATIONAHA.119 044574

18. Chakravarty T, Jilaihawi H, De La Rosa A, Makkar R. Anticoagulation therapy after transcatheter aortic valve replacement. Curr Cardiol Rep. (2020) 22:175. doi: 10.1007/s11886-020-01425-8

19. Yanagisawa R, Hayashida K, Yamada Y, Tanaka M, Yashima F, Inohara $\mathrm{T}$, et al. (2016). Incidence, predictors, and mid-term outcomes of possible leaflet thrombosis after TAVR. JACC Cardiovasc Imag. 10:111. doi: $10.1016 /$ j.jcmg.2016.11005

20. Páez JM, Jorge-Herrero E, Carrera A, Millán I, Rocha A, Calero $\mathrm{P}$, et al. Ostrich pericardium, a biomaterial for the construction of valve leaflets for cardiac bioprostheses: mechanical behaviour, selection and interaction with suture materials. Biomaterials. (2001) 22:273140. doi: 10.1016/S0142-9612(01)00014-X

21. Salaun E, Côté N, Clavel MA, Pibarot P. Biomarkers of aortic bioprosthetic valve structural degeneration. Curr Opin Cardiol. (2019) 34:132-9. doi: 10.1097/HCO0000000000000590 
22. Lam KY, Koene B, Timmermans N, Soliman-Hamad M, Van Straten A. Reintervention after aortic valve replacement: comparison of 3 aortic bioprostheses. Ann Thorac Surg. (2020) 110:615-21. doi: 10.1016/j.athoracsur.2019.10060

23. Rassoli A, Fatouraee N, Guidoin R, Zhang Z. Comparison of tensile properties of xenopericardium from three animal species and finite element analysis for bioprosthetic heart valve tissue. Artif Organs. (2020) 44:27887. doi: 10.1111/aor13552

24. Carnero-Alcázar M, Maroto LC, Cobiella-Carnicer J, Vilacosta I, Nombela-Franco L, Alswies A, et al. Transcatheter versus surgical aortic valve replacement in moderate and high-risk patients: a metaanalysis. Eur J Cardiothorac Surg. (2017) 51:644-52. doi: 10.1093/ejcts/ ezw388

25. Yesiltas MA, Haberal I, Kuserli Y, Yildiz A, Koyuncu AO, Özsoy SD. Comparison of short and mid-term mortality and morbidity in patients with severe aortic stenosis (Intermediate/High Risk) who underwent transcatheter aortic valve replacement and surgical aortic valve replacement. Heart Surg Forum. (2020) 23:212-20. doi: 10.1532/hsf2913

26. Zhang X, Wang T, Lan R, Dai Q, Kang L, Wang L, et al. Meta-analysis comparing results of transcatheter versus surgical aortic-valve replacement in patients with severe aortic stenosis. Am J Cardiol. (2020) 125:44958. doi: 10.1016/j.amjcard.2019.10057

27. Lefevre T, Colombo A, Tchetche D, Latib A, Klugmann S, Fajadet J, et al. Prospective multicenter evaluation of the direct flow medical transcatheter aortic valve system: 12 -month outcomes of the evaluation of the direct flow medical percutaneous aortic valve $18 \mathrm{~F}$ system for the treatment of patients with severe aortic stenosis (DISCOVER) study. JACC Cardiovasc Interv. (2016) 9:68-75. doi: 10.1016/j.jcin.2015.09027

28. Kulling M, Kulling J, Wyss C, Hurlimann D, Reho I, Salzberg S, et al. Effective orifice area and hemodynamic performance of the transcatheter Edwards Sapien 3 prosthesis: short-term and 1-year follow-up. Eur Heart J Cardiovasc Imaging. (2018) 19:23-30. doi: 10.1093/ehjci/jew301
29. Butter C, Tambor G, Neuss M, Kaneko H, Schau T, Hoelschermann F. First successful transfemoral implantation of an Edwards Sapien XT valve in a direct flow valve after early restenosis. JACC Cardiovasc Interv. (2016) 9:e1-2. doi: 10.1016/j.jcin.2015.09029

30. Duran K.araduman B, Ayhan H, Bulguroglu S, Keleş T, Bozkurt E. Transcatheter valve-in-valve implantation Edwards Sapien XT in a direct flow valve after early degeneration. J Card Surg. (2020) 35:35925. doi: 10.1111/jocs 15016

31. Yap J, Southard JA, Wong GB, Singh GD, Stripe BR. Technical considerations for repeat transcatheter aortic valve implantation in a failing Direct Flow Medical transcatheter heart valve. EuroIntervention. (2020) 16:5567. doi: 10.4244/EIJ-D-20-00426

32. Direct Flow Medical Receives CE Mark for Transcatheter Aortic Heart Valve [Online] (2013). Available online at: https://www.dicardiology.com/ article/direct-flow-medical-receives-ce-mark-transcatheter-aortic-heartvalve (accessed February 16, 2021).

33. Direct Flow Medical Announces DISCOVER Trial Three-Year Results [Online] (2016). Available online at: https://www.dicardiology.com/content/ direct-flow-medical-announces-discover-trial-three-year-results (accessed February 16, 2021).

Conflict of Interest: The authors declare that the research was conducted in the absence of any commercial or financial relationships that could be construed as a potential conflict of interest.

Copyright (c) 2021 Edlinger, Bannehr, Wernly, Kücken, Okamoto, Lichtenauer, Hähnel, Reiners, Neuss and Butter. This is an open-access article distributed under the terms of the Creative Commons Attribution License (CC BY). The use, distribution or reproduction in other forums is permitted, provided the original author(s) and the copyright owner(s) are credited and that the original publication in this journal is cited, in accordance with accepted academic practice. No use, distribution or reproduction is permitted which does not comply with these terms. 